WSR C.TR $\cdot 90 \cdot 394$

\title{
BOUNDING BURNOUT RISK POWER LIMITS FOR THE K-14 CYCLE
}

(U)

OCTOBER, 1990

\section{Westinghouse Savannah River Company Savannah River Laboratory Aiken, SC 29808}

Prepared for the II.S. Department of Energy under Contract LE-AC09.88SR18035 


\section{DISCLAIMER}

This report was prepared by the Westinghouse Savannah River Corporation (Westinghouse) for the United States Department of Energy under Contract DE-ACO9-88SR18035 and is an account of work performed that Contract. Neither the United States, the United States Department of Energy, nor Westinghouse, nor any of their employees, makes any warranty, expressed or implied, or assumes any legal liability or responsibility for the accuracy, completeness, or usefulness of any information, apparatus, product, or process disclosed herein, or represents that its use will not infring: privately owned rights. Reference herein to any specific commercial product, process or service by trade name, mark, manufacturer, or otherwise does not necessarily constitute or imply endorsement, recommendation, or favoring of same by Westinghouse or by the United States Government or any agency thereof. The views and opinions of authors expressed herein do not necessarily state or reflect those of the United States Government or any agency thereof. 


\title{
NRTSC \\ NUCLEAR REACTOR TECHNOLOGY AND SCIENTIFIC COMPUTATIONS
}

\author{
Keywords: LOCA LIMITS \\ K-14 LIMITS \\ BOR \\ CHF
}

RETENTION: PERMANENT

\section{BOUNDING BURNOUT RISK POWER LIMITS FOR THE K-14 CYCLE (U)}

B y

M. A. SHADDAY JR.

ISSUED: OCTOBER 1990

Derivative Classifier_. Faraci 10/1/90

SRL SAVANNAH RIVER LABORATORY, AIKEN, SC 29808

Westinghouse Savannah River Company Prepared for the U.S. Department of Energy under Contract DE-AC09-88SR18035 
PROJECT: LOCA

DOCUMENT: WSRC-TR-90-394

TITLE: BOUNDING BURNOUT RISK POWER LIMITS FOR THE K-14 CYCLE

QA TASK NUMBER: 90-023-1

REVISION NUMBER: 0

APPROVALS:

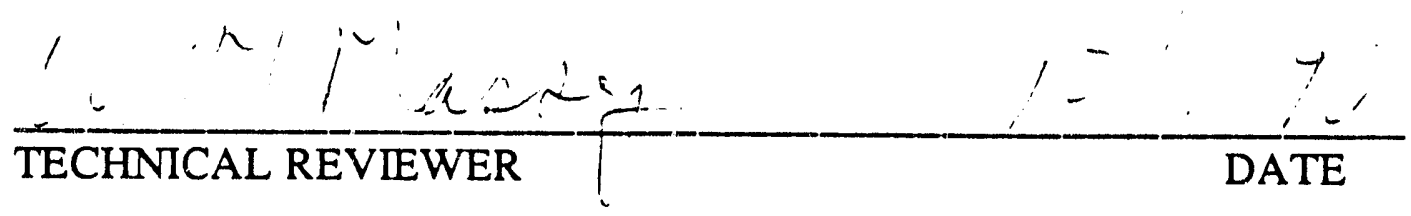

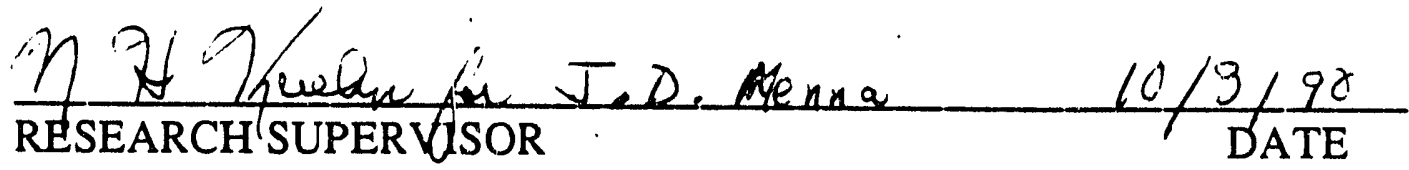

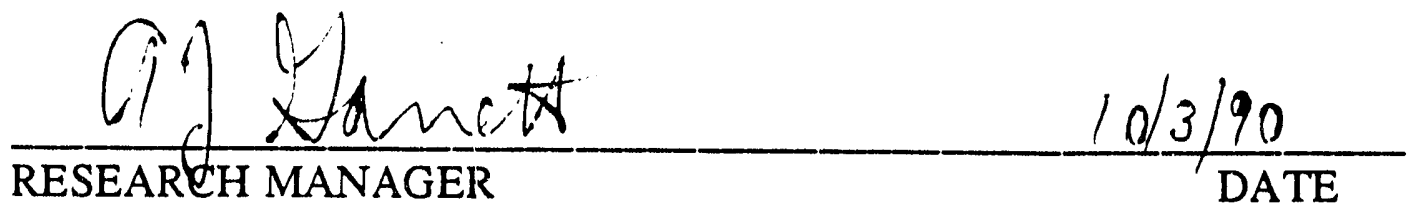




\section{TABLE OF CONTENTS}

1. Introduction and Summary 1

2. Description of Burnout Risk (BOR) Limits 1

3. Bounding BOR Analysis 3

4. BOR Power Limits 9

5. Discussion of BOR Limits 16

6. References 19

7. Addendum 21 


\section{Introduction and Summary}

Burnout risk (BOR) power limits are designed to protect the reactor from a significant release of fission products, due to critical heat flux (CHF) burnout of fuel and target assemblies. At expected operating power levels for reactor restart, approximately $50 \%$ of historical full power, the risk of CHF and attendant burnout is negligible. Flow instability power limits will restrict reactor operation, and flow instability will always oceur before CHF, [1]. BOR power limits must nevertheless be calculated because they are required by the reactor control computer, [2]. Bounding BOR limits have been calculated for the K-14 cycle, to fulfill this requirement, and they are presented in this document. Two sets of BOR limits have been calculated: one applicable for the first subcycle, zero to $30 \%$ fuel burnup, and the other for the second subcycle, $30 \%$ to $55 \%$ fuel burnup.

\section{Description of BOR Limits}

There are two BOR limits for the SRS reactors: tue technical limit prevents core damage from continuous operation at the limit, and the tran: ient protection limit provides a safety margin for accidents that are erminated by the primary scram circuits, [3]. BOR limits are the calct:lated release of activity to the coolant system from film boiling burn ut, $10^{5}$ curies for the technical limit and $10^{7}$ curies for the transient protection limit. These limits are approximately equal to the inventory equivalent to fuel operating at $0.03 \mathrm{MW}$ and $3.0 \mathrm{MW}$ respectively. BOR is quantified by integrating the probability of occurnence of local $\mathrm{CHF}$ over the entire reactor core. The major paraneter in calculating BOR is the nominal burnout safety factor or $B O S$ i $^{N}$. BOSF $F_{N}$ is the ratio of the calculated nominal burnout heat flux to the calculated nominal operating heat flux.

$$
\text { BOSF }_{\mathrm{N}}=\frac{\text { calculated nominal burnout heat flux (CHF) }}{\text { calculated nominal operating heat flux }}
$$

CHF is calculated from empirical correlations, developed at SRL, and the operating heat flux is calculated by an assembly model. A description of the old BOR limits methodology follows, for background purposes. This methodology was not used in this analysis. 
BOSF $F_{N}$ is calculated for an ideal assembly. Nonidealities such as variation in the fuel tube thickness, fuel tube eccentricity, and model deficiencies can influence the onset of local CHF. The nonidealities that are included in the calculation of BOR are discussed in reference [4]. The noridealities are combined statistically by COBAD, the code used to calculate BOR. The following equation illustrates the manner in which BOR is calculated.

BOR $=\sum_{i=1}^{N} \sum_{j=1}^{M} P_{i j} \sum_{k=1}^{L} f_{i j k} P\left[\left(B O S F_{N}\right)_{i j k} \leq U_{i j k}\right]$

BOR - Burnout risk for the reactor, MW.

$\mathrm{N}$ - Number of fuel assemblies.

M - Number of power producing tubes in an assembly.

$L$ - Number of calculational axial layers in an assembly.

$P_{i j}$ - Power of a fuel or target tube, MW.

$\mathrm{f}_{\mathrm{ijk}}$ - Fraction of tube power contributed by the $\mathrm{k}_{\mathrm{th}}$ layer.

$P\left[\left(B O S F_{N}\right) \leq U_{i j k}\right]$ - Probability of burnout in the $k_{t h}$ layer.

$\mathrm{U}_{\mathrm{ijk}}$ - Combined nonideality factor for the $\mathrm{k}_{\mathrm{th}}$ layer.

COBAD calculates the ratio of assembly burnout risk $\left(B O R_{A}\right)$ to the assembly power as a function of the minimum $\mathrm{BOSF}_{\mathrm{N}}$ on the assembly control surface. This relation is used by the reactor control computer to implement the BOR limits. The burnout risk relation has the following functional form:

$$
\frac{\text { BOR }_{A}}{P_{A}}=e^{\left[C_{1}+C_{2} \text { BOSF }_{N}+C_{3}\left(B_{O S F}\right)^{2}\right]}
$$

The control computer calculates the minimum $\mathrm{BOSF}_{\mathrm{N}}$ on the control surface of an assembly from measured operating conditions. The assembly burnout risk is determined with equation 3 , and values of $B O R_{A}$ for the individual assemblies are summed to calculate reactor BOR.

The COBAD based procedure for calculating the $B O R_{A}$ curve is in need of considerable review and revision. COBAD is not a $Q . A$ configuration controlled code, as required for codes used in critical applications, and the methodology should be updated and based on FLOWTRAN, 
the assembly code currently in use. Because of quality assurance concerns, it was not considered prudent to use the old methodology to calculate BOR limits, and time constraints and more pressing priorities precluded development of a new BOR methodology prior to restart. The results of a recent study indicate that BOR is not significant at reactor operating powers anticipated for restart, [1], and a large-scale effort to develop a BOR limits methodology is iherefore not warranted prior to restart. Negligible or otherwise, BOR limits must be implemented by the control computer, and the format is not very flexible. To meet control computer requirements, a bounding analysis to calculate power limits with a negligible burnout risk was conducted. Zero-BOR-BOSF $\mathrm{N}_{\mathrm{N}}$ values were determined for each of the K-14 flowzones, and these were used to develop conservative $\mathrm{BOR}_{\mathrm{A}}$ curves, in the form of equation 3 .

\section{Bounding BOR Analysis}

Zero-BOR-BOSF $F_{N}$ values are calculated by combining assembly nonidealities in the worst possible configuration and determining the threshold power at which CHF is predicted to occur in an assembly. This procedure will result in overly conservative BOR linits, since the configuration of nonidealities is not realistic. It avoids the complicated statistical treatment of uncertainties, required to quantify BOR, and there is plenty of margin between bounding BOR limits and flow instability power limits, such that BOR limits will not restrict reactor operation for the $\mathrm{K}-14$ cycle.

The assembly nonidealities corsidered are: azimuthal variations in assembly power, subchannel flow reduction due to eccentric nesting of the fuel and target tubes, the use of a bounding axial power profile, and uncertainties in the CHF correlation. Azimuthal variations in assembly power result from circumferential variations in fuel and target tube thicknesses and an azimuthal variation in the neutron flux, due to the relative position of control rods. Factors that influence the azimuthal distribution of assembly power in a Mk-22 were treated statistically in the FI uncertainty analysis with rOWCOMB.FOR, [5]. This code was modified to calculate the azimuthal distribution of assembly power for the worst alignment of asymmetric power factors, [1]. The azimuthal distribution of normalized power for the two fuel tubes of a Mk-22 assembly for this configuration are shown in figure 1 . The peak powers are approximately $40 \%$ above nominal. The average inner and outer fuel 
tube power multipliers for the hot quadrant are 1.34769 and 1.3418 respectively.

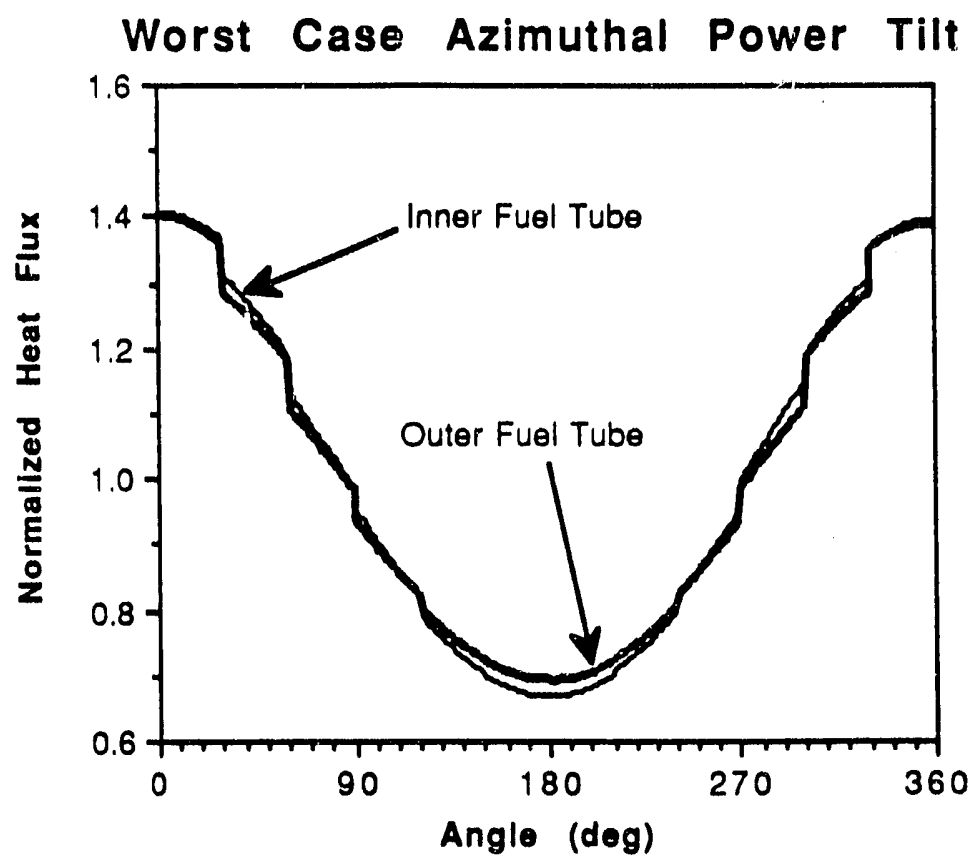

Figure 1. Azimuthal Variation in Power for the Inner and Outer Fuel Tubes

Eccentric positioning of fuel and target tubes can reduce the coolant flow through assembiy sibchannels. The maximum eccentricity will occur when two ribs contact the opposite wall, as shown in figure 2 . This reduces the subchannel cross-sectional areas by approximately $10 \%, 8 \%$, and $11 \%$ respectively for the inner, middle, and outer flow chanrels of a Mk-22 assembly. In this bounding analysis the eccentricity is assumed to exist in the same direction along the entire length of the heated section of the assembly. The flow rate through a pinched subchannel is reduced proportional to the 1.25 power of the area ratio.

$$
\frac{\mathrm{Q}_{\text {Ecc. }}}{\mathrm{Q}_{\text {Nom. }}}=\left(\frac{\mathrm{A}_{\text {Ecc. }}}{\mathrm{A}_{\text {Nom. }}}\right)^{1.25}
$$

The eccentric subchannel flow rate is directly reduced by the reduction in cross-sectional area, and there is a further reduction due to a drop in axial flow velocity. The velocity reduction is due to the fact that the subchannel pressure drop is essentially invariant with 
respect to eccentricity. This is due to the fact that the parallel channels are exposed to the same pressure boundary conditions. The worst assembly configuration for CHF is when the eccentricity and azimuthal power tilt vectors are colinear.

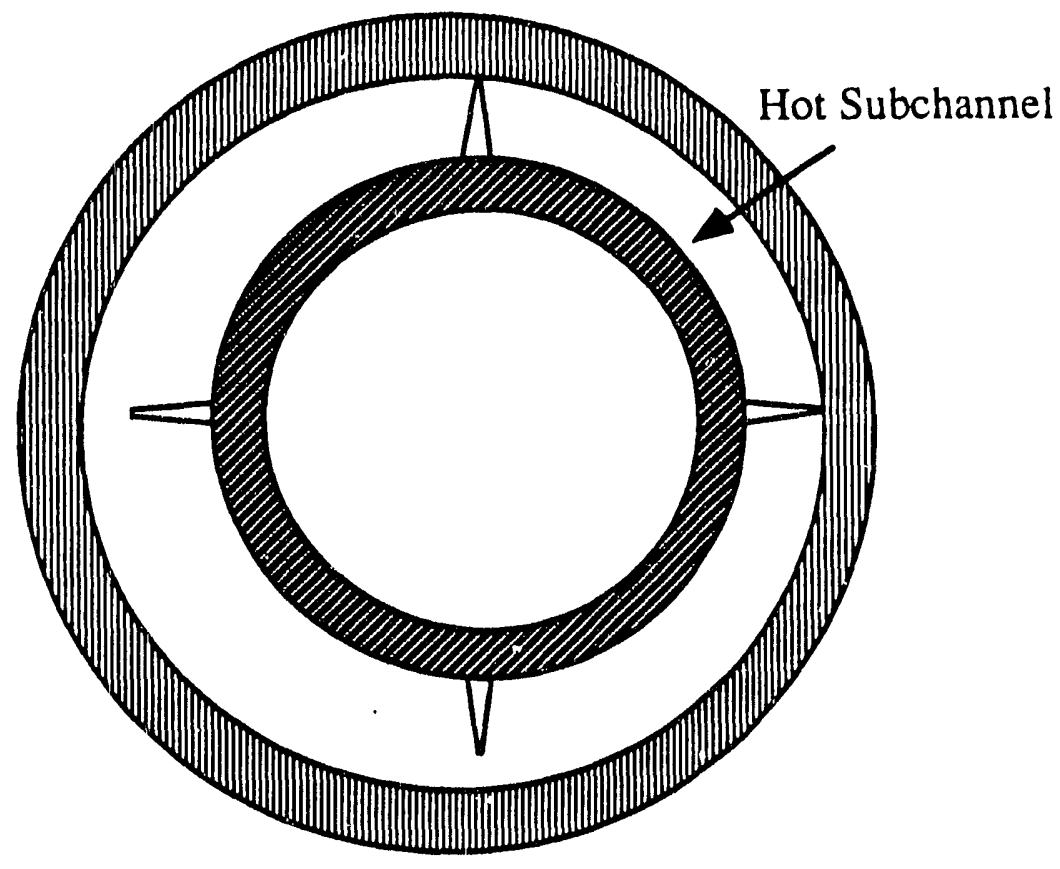

Figure 2. Subchannel with Maximum Eccentricity

The following correlations are used to predict CHF in SRS reactor assemblies.

$$
\mathrm{CHF}=107500(1+0.145 \mathrm{~V})\left[1+0.031\left(\mathrm{~T}_{\text {sat }}-\mathrm{T}_{\mathrm{b}}\right)\right]
$$

or

$$
\mathrm{CHF}=413400(1+0.0515 \mathrm{~V}) \text { for } \mathrm{T}_{\text {sub }} \leq 20^{\circ} \mathrm{C}
$$

where:

$$
\begin{aligned}
& \text { CHF - Critical heat flux, } \frac{\mathrm{pcu}}{\mathrm{hr} \mathrm{ft}^{2}} \\
& \mathrm{~V} \text { - Coolant velocity, } \frac{\mathrm{ft}}{\mathrm{s}} \\
& \mathrm{T}_{\text {sat }} \text { - Saturation temperature, }{ }^{0} \mathrm{C} \\
& \mathrm{T}_{\mathrm{b}} \text { - Bulk fluid temperature, }{ }^{0} \mathrm{C}
\end{aligned}
$$

The correlation uncertainty is included in the bounding BOR analysis. It includes experimental uncertainty in the data used to develop the 
correlations and the uncertainty in the independent variables in the correlation. The CHF correlation has an uncertainty with a standard deviation of $6.5 \%,[6]$. This is the uncertainty in the experimental data. The overall correlation uncertainty is also a function of uncertainty in the flow velocity and subcooling. The influence of assembly nonidcalities on subchannel flow variables is handled by considering the worst case configuration, and therefore is not included in the variable uncertainties. The flow variable uncertainties are the uncertainties in the assembly boundary conditions. The uncertainty in the primary coolant system flow rate has a standard deviation of $863.88 \mathrm{gpm} /$ coolant loop or $3.46 \%$, [7], and this is the assumed uncertainty in the velocity. The uncertainty in pump suction temperature was derived from an analysis of the heat exchangers, and it has a standard deviation of approximately $.5^{\circ}$ $C$, [7]. This is also the uncertainty in the plenum temperature, and is the assumed uncertainty in the subcooling. The local pressure is calculated from the tank bottom pressure, which is a well known quantity, so the uncertainty in the saturation temperature is neglected. The three uncertainties are assumed to be independent, and they are combined together by the root-sum-squares to yield the overall uncertainty in CHF.

$$
\sigma_{\mathrm{CHF}}=\sqrt{\sigma_{\mathrm{Corr}}^{2}+\left(\frac{\partial \mathrm{CHF}}{\partial \mathrm{V}}\right)_{\Delta \mathrm{T}_{\text {sub }}}^{2} \sigma_{\mathrm{V}}^{2}+\left(\frac{\partial \mathrm{CHF}}{\partial \Delta \mathrm{T}_{\text {sub }}}\right)_{\mathrm{V}}^{2} \sigma_{\Delta \mathrm{T}_{\text {sab }}}^{2}}
$$

The value of CHF used in the bounding analysis is the ideal value, predicted by equation 5, minus four standard deviations.

$$
\mathrm{CHF}_{\text {bounding }}=\mathrm{CHF}_{\text {ideal }}-4 \sigma_{\mathrm{CHF}}
$$

The nonidealities previously described have been incorporated into a simple steady-state assembly model, developed to analyze BOR in Mk-22 assemblies. The model is described in detail in reference [1]. Inputs for the model are assembly flow rate, and power, plenum temperature, and tank bottom pressure. Flow is partitioned between the flow channels in accordance with the hydraulics manual, and the axial and radial power distributions are based on those in FLOWTRAN. The model calculates the axial pressure, velocity, and bulk temperature distributions in the three main flow channels. The model was benchmarked against FLOWTRAN, and the predicted flow fields are in good agreement with the more sophisticated assembly 
code. This model was used instead of FLOWTRAN because it was simplier to incorporate nonidealities, had a faster computational turn-around time, and it was adequate for the task.

The axial power profile is a modified sinusoidal function that closely approximates the axial profile that is used in FLOWTRAN fo. FI power limits calculations. This is a bounding power profile. The FLOWTRAN prefile was approximated by a sinusoidal function rather than interpolating, because it is desirable to have an integrable function. The axial power profile is shown in figure 3. Also shown is the FLOWTRAN profile. Radial power splits between the two fuel tubes and between the two surfaces of a fuel tube were benchmarked with FLOWTRAN. These power splits change as fuel is consumed. Three cases were considered: beginning of cycle, $30 \%$ fuel burnup, and $55 \%$ fuel burnup.

\section{Axial Power Distribution (K 14.1)}

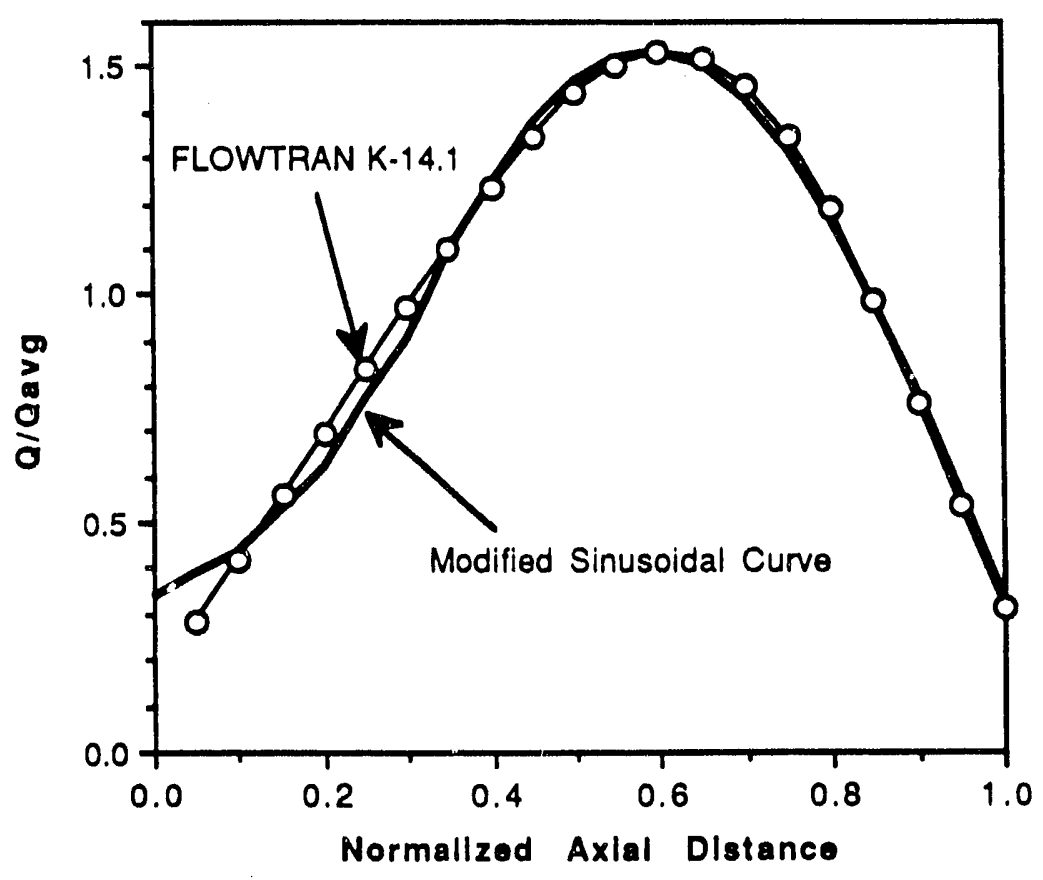

Figure 3. Axial Power Shape in a Mk-22 Assembly

BOR power limits were calculated for each of the K-14 flowzones. The procedure was to run the assembly model, with the hereinbefore nonidealities included, and iteratively determine the assembly power at which the minimum value of $\mathrm{BOSF}_{\mathrm{N}}$ is equal to one. This is the 
bounding assembly technical power limit for the applicable flowzone. The Zero-BOR-BOSF $F_{N}$ value was determined with the ideal assembly model. This parameter is the minimum $\mathrm{BOSF}_{\mathrm{N}}$ on the assembly control surface, which for the Mk-22 assembly is the inner surface of the outer fuel tube. This is the surface with the least change in the minimum $\mathrm{BOSF}_{\mathrm{N}}$ over the subcycle. To calculate the $\mathrm{BOR}_{\mathrm{A}}$ curve, a very steep and consequently conservative shape was assumed, and coefficients for equation 3 were calculated that are compatable with the control computer.

The same $B O R_{A}$ curve is used for both technical and transient protection limits. This is accomplished with the TRAM coefficient, which is the ratio of the steady-state $B O S F_{N}$ to the transieni $B O S F_{N}$. The BOSF $F_{N}$ is modified by TRAM so that the transient protection $B O R$ ran be evaluated with the technical limits $B O R_{A}$ curve.

$$
\operatorname{BOSF}_{N_{\text {tremient }}}=\frac{\mathrm{CHF}}{\text { TRAM } \times \dot{Q}_{\text {operating }}}=\frac{\operatorname{BOSF}_{N_{s}}}{T R A M}
$$

A DEGB LOCA is the design basis accident for reactor power limits, and the severest mismatch between power and coolant flow occurs just before the control rods are inserted during the FI phase of this accident, at approximately 1.3 seconds. The assembly power is essentially at the preincident level, and the coolant flow rate and tank bottom pressure are significantly reduced. This is the accident that was used to calculate BOR transient protection limits. At 1.3 seconds into a LOCA, the assembly would essentially be operating at quasi-equilibrium conditions. This was demonstrated by comparing the output of the simple steady-state assembly code, used in this analysis, with the transient solution of FLOWTRAN. The agreement was very good, and therefore the simple assembly code is adequate for calculating transient protection limits. The boundary conditions for calculating these limits are: assembly flow rate of $225.0 \mathrm{gpm}$, tank bottom pressure of 19.5 psia, and the preincident plenum temperature. The TRAM coefficient is designed so that the transient BOSF $_{N}$ will equal the steady-state Zero-BOR-BOSF ${ }_{N}$ when the assembly is operating at the transient CHF power limit. 


\section{CHF Power Limits}

Zero-BOR-BOSF $F_{N}$ values for each of the six K-14 flowzones were calculated for beginning and end of subcycle conditions and with plenum temperatures of $20^{\circ} \mathrm{C}$ and $40^{\circ} \mathrm{C}$. The $\mathrm{K}-14$ cycle consists of two subcycles: K-14.1 from zero to $30 \%$ fuel burnup, and $\mathrm{K}-14.2$ from $30 \%$ to $55 \%$ fuel burnup. Beginning and end of subcycle conditions bracket expected operating conditions for the subcycles, and the most conservative results were used to calculate BOR limits for each subcycle. The assemblies in flowzones 1 through 3 have bottom end fittings (BEF) with 36 shellholes and the flowzone 4 through 6 assemblies have BEF's with 28 shellholes. The number of shellholes influences the form losses in the BEF, and therefore the axial. pressure distribution in the assembly. Flowzone flow parameters are given in table 1:

$\begin{array}{ccr}\text { FLOWZONE } & \mathrm{T}_{\text {in }}\left({ }^{\circ} \mathrm{C}\right) & \text { FLOW }(\mathrm{gpm}) \\ 1 & 20 & 339.20490 \\ 1 & 40 & 345.07823 \\ 2 & 20 & 348.14581 \\ 2 & 40 & 354.30198 \\ 3 & 20 & 362.02150 \\ 3 & 40 & 368.52076 \\ 4 & 20 & 342.93377 \\ 4 & 40 & 348.74685 \\ 5 & 20 & 361.25068 \\ 5 & 40 & 367.49463 \\ 6 & 20 & 363.22813 \\ 6 & 40 & 369.41193\end{array}$

Table 1. K 14.1 Flowzone Flow Rates

Steady-state BOR power limits were calculated with the nonideal configuration of the assembly code. The tank bottom pressure was the nominal value of $28.5 \mathrm{psia}$, and the plenum temperatures and flow rates were values from table 1 . These power limits are the thresholds at which CHF is predicted to occur for extreme nonideal bounding conditions. Minimum BOSF $\mathrm{N}_{\mathrm{N}}$ values were then calculated, using the ideal assembly model and the bounding power limits. The surface on which these minimums occur changes with fuel burnup; at 
the beginning of the cycle the closest approach to CHF occurs on the outer surface of the outer fuel tube, and with $55 \%$ burnup the closest approach to CHF occurs on the inner surface of the inner fuel tube. At $30 \%$ burnup the closest approach to CHF occurs on the inner surface of the inner fuel tube, but the outer surface of the outer fuel tube is almost as close. The control computer calculates the $\mathrm{BOSF}_{\mathrm{N}}$ on the control surface, the inside surface of the outer fuel tube, and the minimum $\mathrm{BOSF}_{\mathrm{N}}$ on this surface is also calculated. This is the ZeroBOR-BOSF $F_{N}$.

Calculated minimum BOSF $_{N}$ results for both the citical surface $\left(B O S F_{N_{\min }}\right)$ and the control surface $\left(B O S F_{N_{c s}}\right)$ are shown in table 2. The more conservative values of Zero-BOR-BOSF ${ }_{\mathrm{N}}$, for all flowzones, are for the cases with a plenum temperature of $40^{\circ} \mathrm{C}$ and therefore only these results are shown.

$\begin{array}{lllllll}\mathrm{FZ} & \mathrm{T}_{\text {in }} & \text { FLOW } & \text { POWER } & \text { BOSF }_{\mathrm{Nm}_{\min }} & \text { BOSF }_{\mathrm{Na}} & \text { \% BURNUP } \\ 1 & 40 & 345.0 & 5.56 & 2.682 & 3.148 & 0 \\ 1 & 40 & 345.0 & 5.84 & 2.680 & 3.114 & 30 \\ 1 & 40 & 345.0 & 5.46 & 2.651 & 3.546 & 55 \\ 2 & 40 & 354.3 & 5.73 & 2.679 & 3.149 & 0 \\ 2 & 40 & 354.3 & 6.02 & 2.676 & 3.114 & 30 \\ 2 & 40 & 354.3 & 5.63 & 2.648 & 3.545 & 55 \\ 3 & 40 & 368.5 & 5.98 & 2.683 & 3.160 & 0 \\ 3 & 40 & 368.5 & 6.29 & 2.676 & 3.121 & 30 \\ 3 & 40 & 368.5 & 5.89 & 2.645 & 3.545 & 55 \\ 4 & 40 & 348.7 & 5.73 & 2.683 & 3.149 & 0 \\ 4 & 40 & 348.7 & 6.02 & 2.680 & 3.114 & 30 \\ 4 & 40 & 348.7 & 5.62 & 2.656 & 3.554 & 55 \\ 5 & 40 & 367.5 & 6.08 & 2.682 & 3.157 & 0 \\ 5 & 40 & 367.5 & 6.39 & 2.678 & 3.121 & 30 \\ 5 & 40 & 367.5 & 5.98 & 2.648 & 3.548 & 55 \\ 6 & 40 & 369.4 & 6.11 & 2.685 & 3.161 & 0 \\ 6 & 40 & 369.4 & 6.42 & 2.682 & 3.127 & 30 \\ 6 & 40 & 369.4 & 6.01 & 2.651 & 3.553 & 55\end{array}$

Table 2. Steady-state Bounding CHF Limits 
where:

$$
\begin{aligned}
& \text { BOSF }_{N_{\text {min }}} \text { is the minimum value on the critical surface } \\
& \text { BOSF }_{N_{c s}} \text { is the minimum value on the control surface }
\end{aligned}
$$

The highest CHF power limits occur with $30 \%$ burnup. This is due to the fact that both the inner surface of the inner fuel tube and the outer surface of the outer fuel tube reach CHF almost simultaneously. The radial power distribution is more favorable, with respect to BOR, at $30 \%$ burnup than at the beginning or the end of the cycle. There is only a slight decrease in the Zero-BOR-BOSF $F_{N}$ between zero and $30 \%$ burnup, despite the significant increase in $\mathrm{CHF}$ power limits, and this is due to the fact that the minimum control surface $B O S F_{N}$ increases with $f_{L}$ :el burnup. Figure 4 shows that the minimum BOSF $_{N}$ increases essentially linearly, with pr rcent hurnup, for constant assembly flow and power parameters.

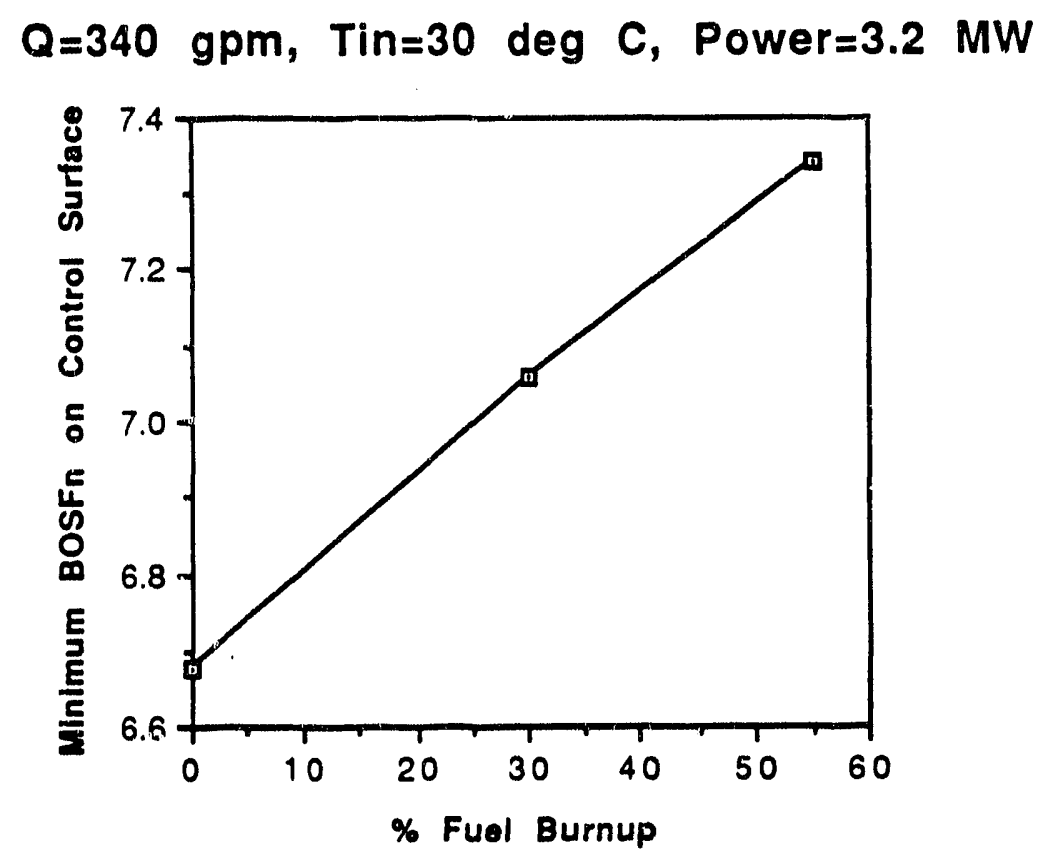

Figure 4. Minimum Control Surface $\mathrm{BOSF}_{\mathrm{N}}$ as a Function of Percent Fuel Burnup.

Figure 5 shows the Zero-BOR-BOSF ${ }_{N}$ values for the six flowzones, as functions of burnup. The most conservative or maximum values occur at the end of cycle, 55\% burnup, and it would appear at first glance most prudent to use these values for the whole cycle. The margin between the transient protection $\mathrm{BOSF}_{\mathrm{N}}$, at FI power limits, 
and the Zero-BOR-BOSF $F_{N}$ is approximately the same for beginning and end of cycle conditions. Because the $\mathrm{BOSF}_{\mathrm{N}}$ increases with burnup during the reactor cycle, the apparent margin would be less at the beginning of the cycle, if the end of cycle Zero-BOR-BOSF $F_{N}$ was used. For this reason separate $B_{A} O R_{A}$ curves are calculated for the two subcycles.

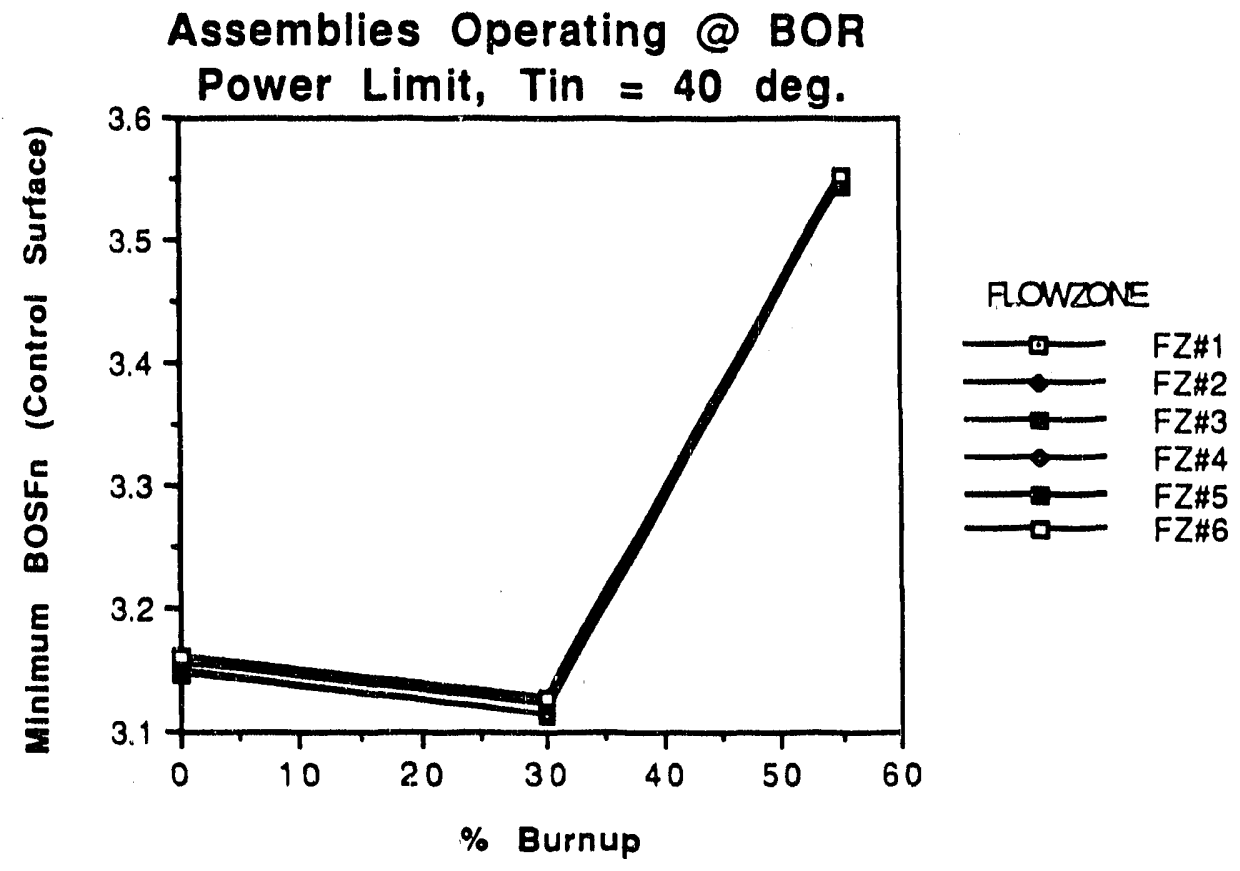

Figure 5. Zero-BOR-BOSF $F_{\mathrm{N}}$ as Functions of Percent Fuel Burnup.

Zero-BOR-BOSF $F_{N}$ values for the six flowzones, at a specified burnup, are very close to each other, therefore a single value will be used for all flowzones. This allows a single $\mathrm{BOR}_{\mathrm{A}}$ curve to be used, which is consistent with past practice. The more conservative value of ZeroBOR-BOSF $F_{N}$ for the K-14.1 subcycle occurs at the beginning of the subcycle, and the more conservative value for the $\mathrm{K}-14.2$ subcycle occurs at the end of the subcycle.

\section{Zero-BOR-BOSF $(\mathrm{K}-14.1)=3.16$$$
\text { Zero-BOR-BOSF }(\mathrm{K}-14.2)=3.55
$$

The control computer requires that the $\mathrm{BOR}_{\mathrm{A}}$ curve have the form of equation 3. Since finite BOR cannot be quantified by this simple 
analysis, the $\mathrm{BOR}_{\mathrm{A}}$ curve can only be approximated conservatively. Control computer requirements constrain the size of the constants in the $\mathrm{BOR}_{\mathrm{A}} / \mathrm{P}_{\mathrm{A}}$ function, equation 3 , to values between -327.67 and 327.67. The constants were solved for by specifying three points on the curve. Zero-BOR-BOSF $F_{N}$ is the value of $B O S F_{N}$ where $B O R_{A} / P_{A}$ is defined as $10^{-6},[3]$, and a value of BOSF $_{N} .1$ less than Zero-BOR-BOSF was assumed to have a corresponding value of $B O R_{A} / P_{A}$ of 0.1 . This second point is arbitrary but, as will be seen later, the resultant $B O R_{A}$ curve is conservative. An intermediate point was chosen, such that the $\mathrm{BOR}_{\mathrm{A}}$ constants satisfied the control computer constraints. The $B O R_{A}$ curve for the $\mathrm{K}-14.1$ subcycle is:

$$
\begin{aligned}
& \frac{\text { BOR }_{A}}{P_{A}}=e^{\left[C_{1}+C_{2} \text { BOSF }_{N}+C_{3}\left(B_{O S F}\right)^{2}\right]} \\
& C_{1}=: 18.96 \\
& C_{2}=33.51 \\
& C_{3}=-23.89
\end{aligned}
$$

The $\mathrm{BOR}_{\mathrm{A}}$ curve for the $\mathrm{K}-14.2$ subcycle is:

$$
\begin{aligned}
& \frac{\mathrm{BOR}_{\mathrm{A}}}{\mathrm{P}_{\mathrm{A}}}=\mathrm{e}^{\left[\mathrm{C}_{1}+\mathrm{C}_{2} \mathrm{BOSF}_{\mathrm{N}}+\mathrm{C}_{3}\left(\mathrm{BOSF}_{\mathrm{N}}\right)^{2}\right]} \\
& \mathrm{C}_{1}=102.13 \\
& \mathrm{C}_{2}=52.27 \\
& \mathrm{C}_{3}=-23.89
\end{aligned}
$$

These curves are shown in figure 6. Figure 7 shows the bounding $B O R_{A}$ curves along with a curve calculated by the old COBAD methodology for the K-14 cycle, [8]. The steepness of the new curves, relative to the old one, is a measure of the degree of conservatism of these bounding $\mathrm{BOR}_{\mathrm{A}}$ curves. 


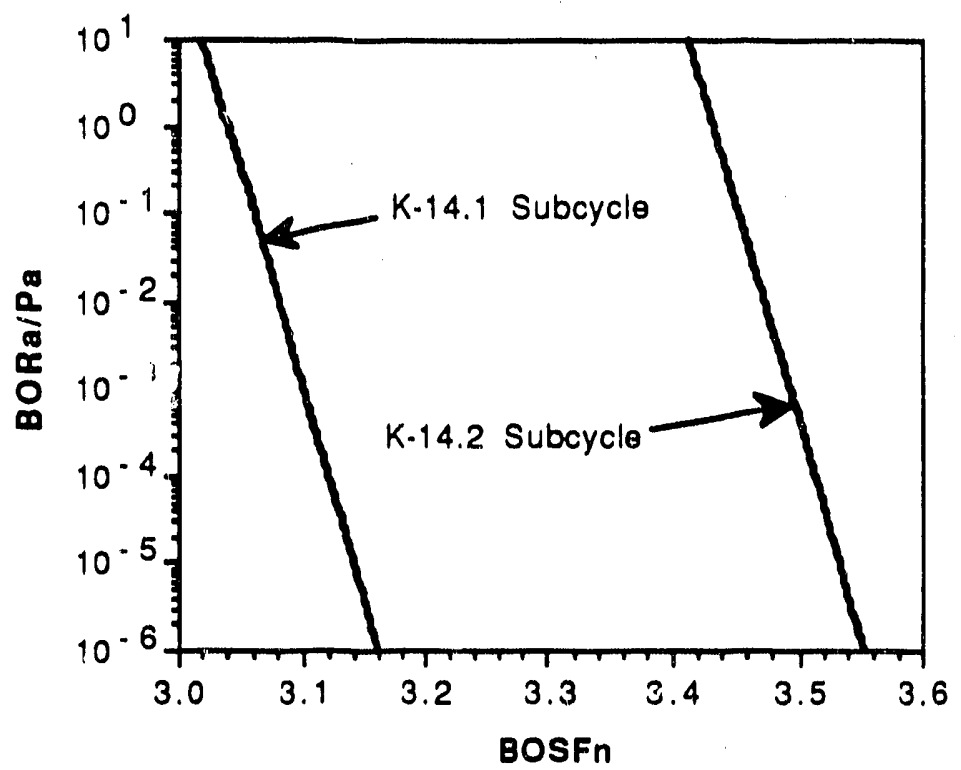

Figure 6. Bounding $\mathrm{BOR}_{\mathrm{A}}$ Curves for the Two K-14 Subcycles.

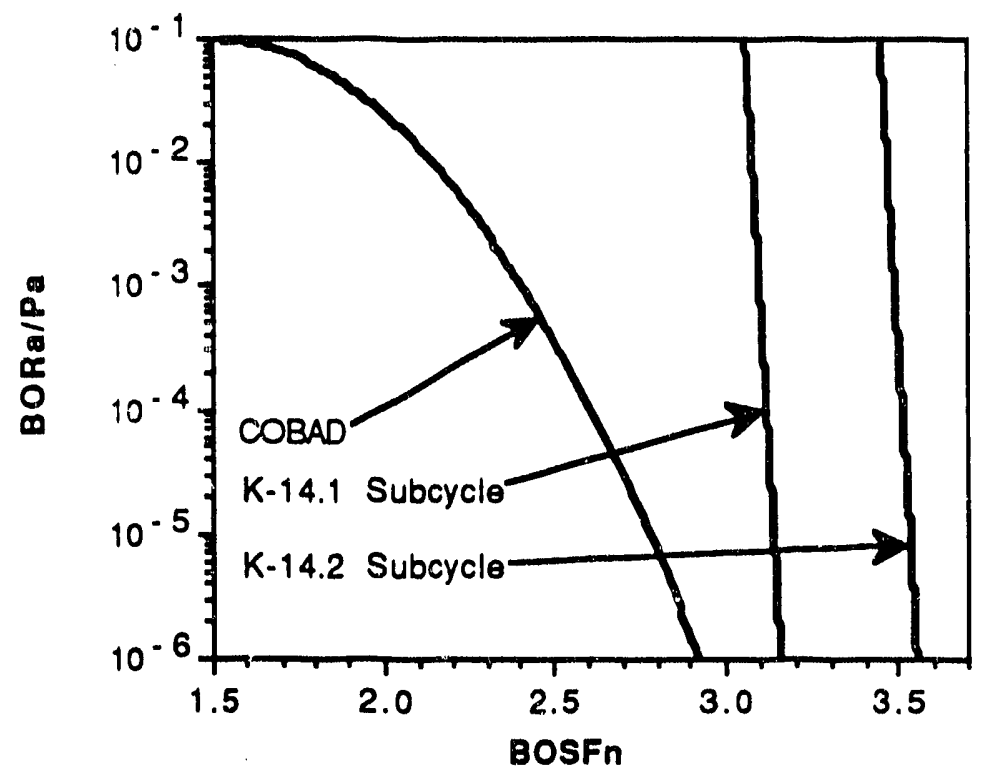

Figure 7. Comparison of Bounding and $\mathrm{COBAD} \mathrm{BOR}_{\mathrm{A}}$ Curves.

Bounding transient protection CHF power limits, for each of the subcycles, were calculated with the nonideal version of the assembly model. The assumed flow conditions were the most severe expected in a LOCA transient prior to scram, an assembly flow of $225 \mathrm{gpm}$ and a tank bottom pressure of 19.5 psia. The plenum temperature was 
assumed to be $40^{\circ} \mathrm{C}$. Since the flow conditions were assumed to be the same for all flowzones, only two cases were considered, 36 shellholes for flowzones \#1-3 and 28 shellholes for flowzones \#4-6. The transient protection CHF power limits are insensitive to the number of shellholes in the BEF, and therefore there is one power limit for each value of burnup. The transient protection CHF power limits for zero, $30 \%$, and $55 \%$ burnup are respectively: $4.03 \mathrm{MW}, 3.94$ $\mathrm{MW}$, and 3.65 MW. Transient values of Zero-BOR-BOSF $F_{N}$ were determined with the ideal assembly model, using the same flow conditions as the steady-state Zero-BOR-BOSF $F_{N}$ calculations and the transient power limits. The TRAM coefficient is the ratio of the transient Zero-BOR-BOSF $F_{N}$ to the steady-state Zero-BOR-BOSF . This TRAM coefficient is defined differently than those derived in the past for use with COBAD/DITTY-BOP CHF power limits, though it is utilized in the same manner by the control computer to calculate transient protection BOR. Transient protection BOR is now based on a DEGB LOCA as opposed to a reactor power increase incident, previously defined as the limiting accident. The redefinition of TRAM was necessitated by the change in the limiting accident.

$$
\begin{aligned}
& \text { Zero-BOR-BOSF }{ }_{\mathrm{N}_{\mathrm{ss}}}=\frac{\mathrm{CHF}(@ \mathrm{SS} P \mathrm{PL})}{\dot{\mathrm{Q}}_{\mathrm{SS} \mathrm{PL}}}=\frac{\mathrm{CHF}(@ \text { Trans PL) }}{\mathrm{TRAM} \times \dot{\mathrm{Q}}_{\text {Trans PL }}} \\
& \text { Zero-BOR-BOSF } \text { N Trans }=\frac{\mathrm{CHF} \text { (@ Trans PL) }}{\dot{\mathrm{Q}}_{\text {Trans PL }}} \\
& \therefore \text { TRAM }=\frac{\text { Zero-BOR-BOSF }}{\text { Zero-BOR-BOSF }_{\mathrm{N}_{\text {Trs }}}}
\end{aligned}
$$

The lower transient protection CHF power limit, for a subcycle, was used to calculate transient Zero-BOR-BOSF ${ }_{N}$ values for each of the flowzones. TRAM coefficients were calculated by ratioing the transient Zero-BOR-BOSF $\mathrm{N}_{\mathrm{N}}$ values to the steady-state Zero-BOR-BOSF values. The $\mathrm{K}-14.1$ TRAM values are presented in table 3 , and the $\mathrm{K}$ 14.2 TRAM values are presented in table 4. 


$\begin{array}{cccc}\text { FLOWZONE } & \text { FLOW }(\mathrm{gpm}) & \text { Zero-BOR-BOSF } & \text { TRAM } \\ & & & \\ 1 & 345.0 & 4.8921 & 1.548 \\ 2 & 354.3 & 5.0724 & 1.605 \\ 3 & 368.5 & 5.3510 & 1.693 \\ 4 & 348.7 & 5.0723 & 1.605 \\ 5 & 367.5 & 5.4498 & 1.724 \\ 6 & 369.4 & 5.4880 & 1.736\end{array}$

Table 3. K-14.1 TRAM Values

FLOWZONE FLOW (gpm) Zero-BOR-BOSF Nuras TRAM

$\begin{array}{llll}1 & 345.0 & 5.8997 & 1.660 \\ 2 & 354.3 & 6.1119 & 1.720 \\ 3 & 368.5 & 6.4378 & 1.811 \\ 4 & 348.7 & 6.1107 & 1.719 \\ 5 & 367.5 & 6.5532 & 1.844 \\ 6 & 369.4 & 6.5984 & 1.857\end{array}$

Table 4. K-14.2 TRAM Values

\section{Discussion of CHF Limits}

Reactor operating power for the $\mathrm{K}-14.1$ subcycle should be determined by FI power limits, therefore the relationship between reactor operation at FI power limits and CHF limits was investigated. FI power limits are assembly effluent temperature limits, as functions of the assembly inlet temperatures, [9], and there are distinct limits for each of the six K-14.1 flowzones. The effluent temperature limits can easily be converted to assembly power limits by:

$$
\text { Power }=\dot{m} C_{p}\left(T_{\text {eff }}-T_{\text {in }}\right)
$$

Table 5 list the hydraulic characteristics and assembly power limits for the K-14.1 flowzones. The ideal assembly model was run with the flow conditions and FI power limits listed in table 5, to determine 
the minimum values of the steady-state and transient protection $B O S F_{N}$ on the control surface. The transient protection $B O S F_{N}$ was calculated from equation 7 , and minimum values of the control surface tranisient protection $\mathrm{BOSF}_{\mathrm{N}}$ were calculated for both be isinning and end of subcycle conditions, for both subcycles. These results are shown in figures 8 and 9 , for the K-14.1 and K-14.2 subcycles respectively. The smallest margins between the transient protection $\mathrm{BOSF}_{\mathrm{N}}$ and the Zero-BOR-BOSF $\mathrm{N}$ are .75 for the $\mathrm{K}-14.1$ subcycle and .32 for the $\mathrm{K}-14.2$ subcycle. In both cases the minimum transient protection $\mathrm{BOSF}_{\mathrm{N}}$ occurs at the beginning of the subcycle, in flowzone \#3, and with an inlet temperature of $20^{\circ} \mathrm{C}$. If end of cycle $\mathrm{BCR}$ limits are applied to the whole cycle, the smallest margin between the transient protection $\mathrm{BOSF}_{\mathrm{N}}$ and the Zero-BOR-BOSF would be .11. There is almost a threefold increase in this margin if separate CHF limits are applied to each subcycle.

$\begin{array}{cllll}\text { FLOWZONE } & \mathrm{T}_{\text {in }} & \mathrm{T}_{\text {eff }} & \mathrm{Q}(\mathrm{gpm}) & \text { Power Limit (MW) } \\ 1 & 20 & 55.34 & 339.2 & 3.4998 \\ 1 & 30 & 61.91 & 342.2 & 3.182 \\ 1 & 40 & 68.48 & 345.1 & 2.856 \\ 2 & 20 & 55.0 & 348.1 & 3.557 \\ 2 & 30 & 61.6 & 351.2 & 3.234 \\ 2 & 40 & 68.2 & 354.3 & 2.903 \\ 3 & 20 & 54.84 & 362.0 & 3.682 \\ 3 & 30 & 61.46 & 365.3 & 3.349 \\ 3 & 40 & 68.08 & 368.5 & 3.007 \\ 4 & 20 & 55.54 & 342.9 & 3.558 \\ 4 & 30 & 62.11 & 345.8 & 3.236 \\ 4 & 40 & 68.68 & 348.7 & 2.906 \\ 5 & 20 & 52.0 & 361.3 & 3.376 \\ 5 & 30 & 58.85 & 364.4 & 3.064 \\ 5 & 40 & 65.7 & 367.5 & 2.744 \\ 6 & 20 & 51.84 & 363.2 & 3.376 \\ 6 & 30 & 58.85 & 364.4 & 3.064 \\ 6 & 40 & 65.7 & 367.5 & 2.744\end{array}$

Table 5. Flowzone Flow Characteristics at FI Power Limits 


\section{K-14.1 Subcycle}

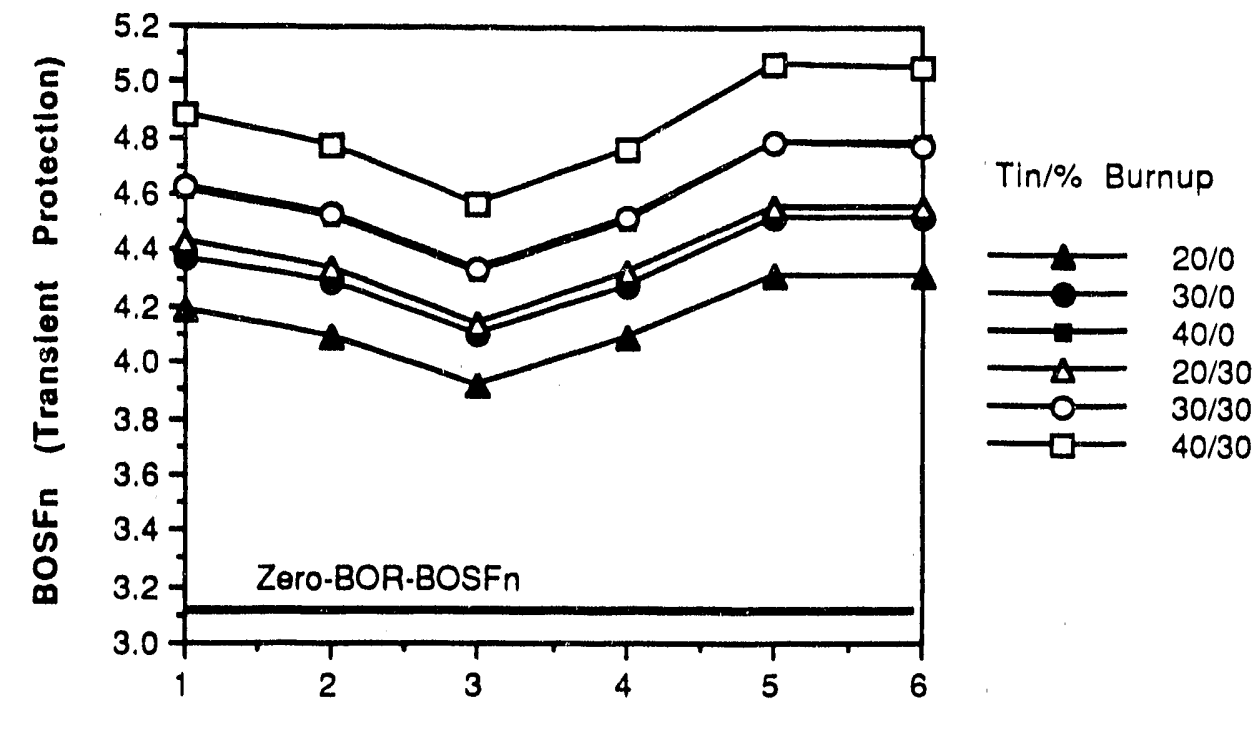

FLOWZONE \#

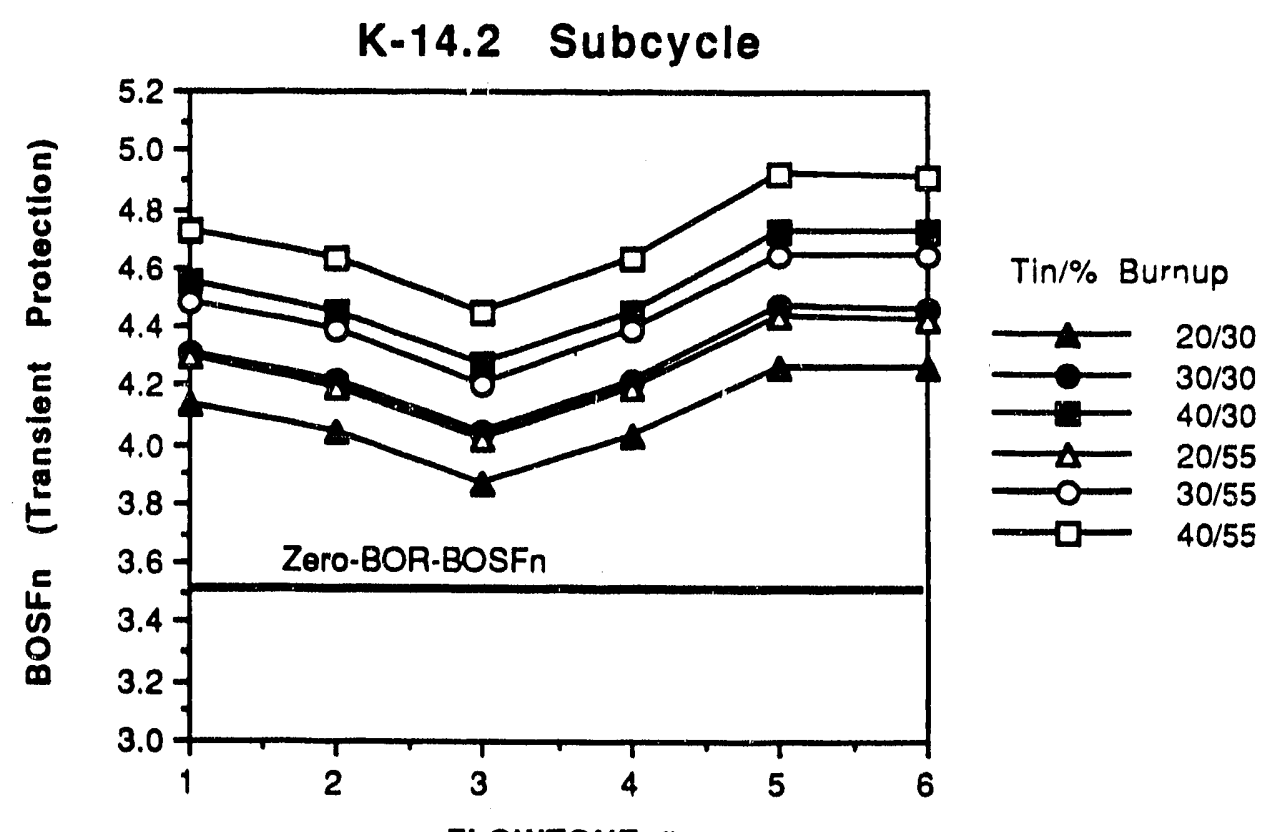

FLOWZONE \#

Figures $8 \&$ 9. Transient Protection BOSF $_{\mathrm{N}}$ for Assemblies Operating at the K-14.1 LOCA-FI Power Limits.

Bounding zero-BOR technical and transient protection assembly power limits have been calculated for the $\mathrm{K}-14$ cycle. The reactor 
control computer implements these limits with the $\mathrm{BOR}_{\mathrm{A}}$ curve, which is used to quantify BOR. Finite BOR cannot be quantified with this bounding analysis, so conservative $\mathrm{BOR}_{\mathrm{A}}$ curves, compatable with control computer requirements, were developed. The only point on the BOR $_{A}$ curve with a technical basis is the Zero-BOR-BOSF $F_{N}$. The rest of the curve meets two criteria; it is conservative, and it is compatable with the control computer. The $B R_{A}$ curve is steep enough such that the transient protection BOR limit, 3.0 MW, would be quickly reached if the transient protection $B O S F_{N}$ dropped below the Zero-BOR-BOSF $F_{N}$. The bounding zero-BOR assembly power limits are essentially the BOR assembly power limits.

To convert assembly power limits to reactor power limits the concept of the number of effective tubes is used, [10]. The number of effective tubes is a multiplier for the assembly power limit that gives the reactor power. Implicit in this multiplier are assumptions about the spatial reactor power distribution, and 400 is a commonly accepted value for a Mk-22 charge. The minimum transient protection assembly power limit is $3.65 \mathrm{MW}$. This corresponds to a zero-BOR reactor power limit of $1460 \mathrm{MW}$. As long as the reactor power remains below this value, the $B R_{A}$ curve will not be exercised. This is approximatelv $61 \%$ of historical full power, and $\mathrm{K}$ Reactor is expected to operate in the neighborhood of $50 \%$, so $\mathrm{BOR}$ power limits should not restrict reactor operation.

\section{REFERENCES}

1. M. A. Shadday, Critical Heat Flux Concerns During the Flow Instability Phase of a DEGB LOCA, WSRC-TR-90-297, August 1990.

2. M. L. Nadeau, F. D. Benton, Reactor Engineering Implementation of the Upgraded Limits System for K-14.1 Reactor Restart, Memo to D. J. Baker, OPS-RTS-900007, May 24, 1990.

3. Technical. Transient Protection, and Confinement Protection Limits for SRP Reactors. DPSTM-110, September 1988.

4. J. M. Boswell, Bases for Nonidealities used in Technical and Transient Protection Limits, DPST-70-304, February 111971. 
5. B. J. Hardy, Documentation of Computer Code POWCOMP.FOR, Memo to N. H. Kuehn, NES-RFI-890133, November 1989.

6. M. W. Hodges, Effect of Rib on Burnoui Heat Flux, DPST-71-317, April 8, 1971.

7. M. A. Shadday, The Impact of Cavitation During a DEGB LOCA, With Uncertainties, WSRC-RP-89-1313, December 1989.

8. J. R. Chandler, Limits Factors for the K-14 Cycle, RTR-2558, May 16, 1988.

9. W. M. Massey, Assembly Temperature Limits for the Flow Instability Portion of the Design Basis Loca: K-14.1 Subcycle, WSRC-RP-90-577, June 1990.

10. W. M. Massey, Revised Equations for Estimating Reactor Power, RTR-2174, August 24, 1989. 


\section{Addendum}

Final FI power limits for the K-14.1 subcycle have not been calculated, and consequently flowzone parameters such as mean and minimum assembly flow rates have not been finalized. As this document was going to press, the nominal and minimum assembly flow rates for the K-14.1 flowzones were changed to the following values:

$\begin{array}{ccc}\text { FLOWZONE } & \text { FLOW }(\mathrm{gpm}) & \text { MIN. FLOW }(\mathrm{gpm}) \\ 1 & 332 & 321.8 \\ 2 & 334 & 323.1 \\ 3 & 344 & 331.5 \\ 4 & 335 & 324.8 \\ 5 & 348 & 336.3 \\ 6 & 348 & 336.2\end{array}$

CHF power limits and Zero-BOR-BOSF $F_{N}$ values for zero\% and $55 \%$ burnup were calculated, using the minimum flowzone assembly flow rates. The Zero-BOR-BOSF ${ }_{\mathrm{N}}$ values for the $\mathrm{K}-14.1$ and $\mathrm{K}-14.2$

subcycles were 3.153 and 3.553 respectively. Since these values are not greater than the Zero-BOR-BOSF $F_{N}$ values presented in the main body of this document, they are not more limiting, and the limits presented in this document are good. If flowzone parameters are redefined before $\mathrm{K}$ Reactor restart, the CHF power limits must be checked to insure that they are conservative. 


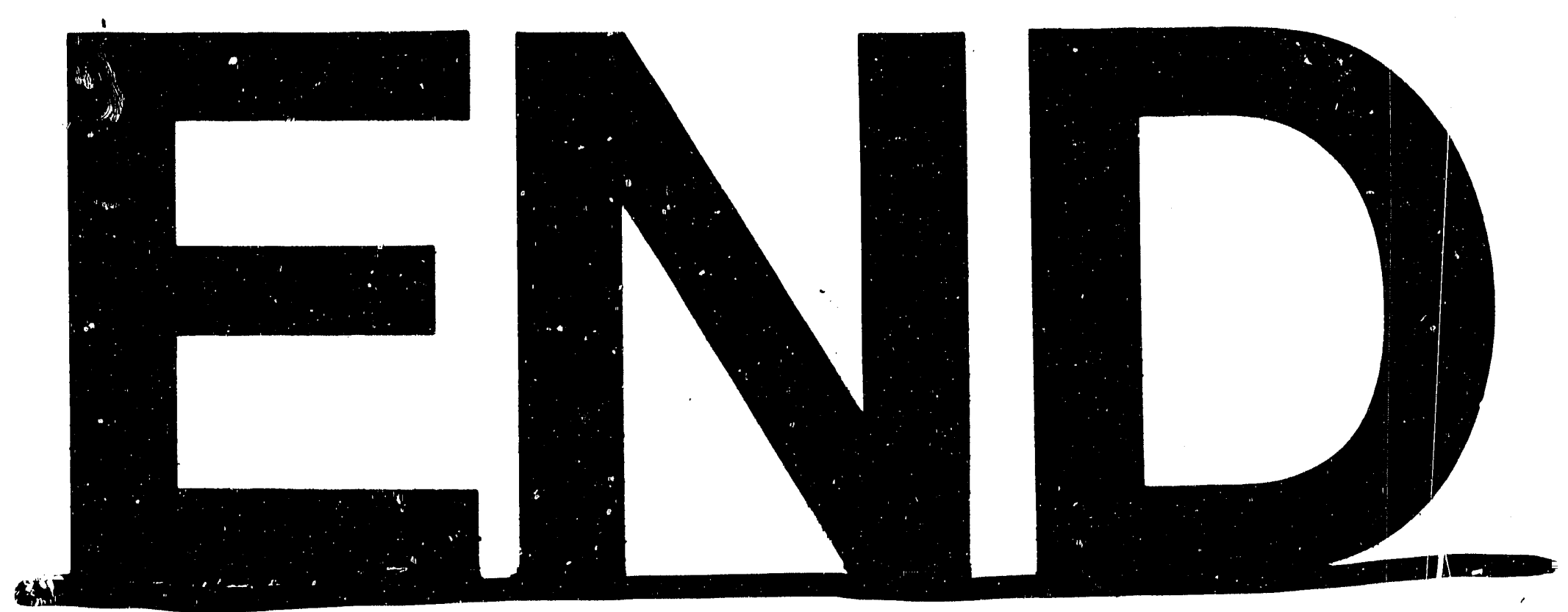

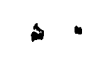
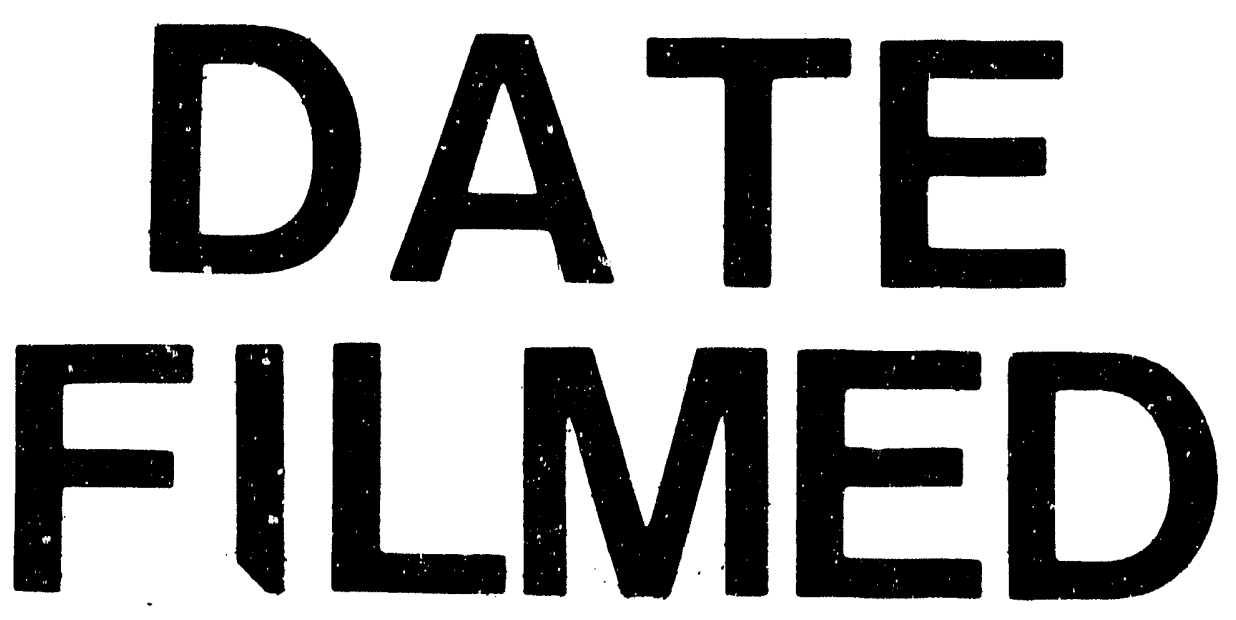

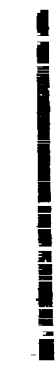

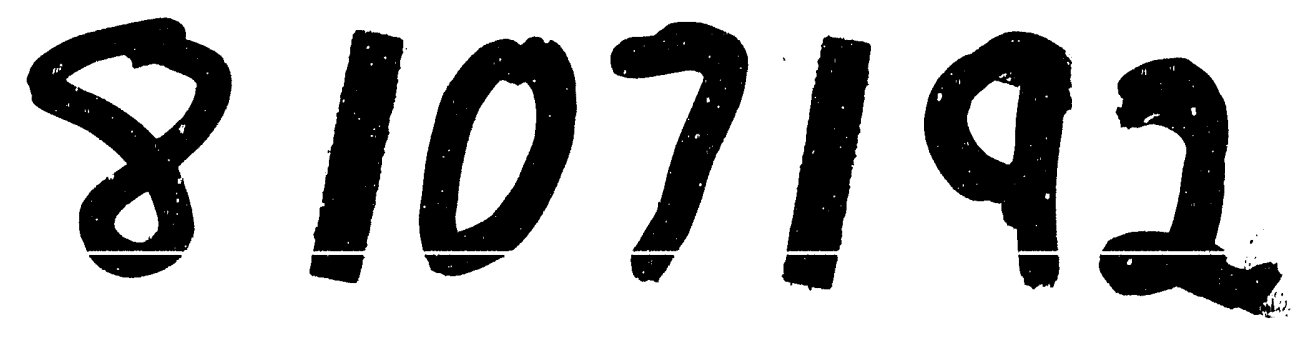




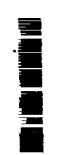

